\title{
Comparative study of flank wear, tool life and type of chips for two similar turning inserts from different producers
}

\author{
Karel Šramhauser ${ }^{1, *}$, Nataša Náprstková $^{1}$, Pavel Kraus ${ }^{1}$, Martin Marek ${ }^{1}$ \\ ${ }^{1}$ J. E. Purkyně Univerzity in Ústí nad Labem, Faculty of Mechanical Engineering, Pasteurova 3334/7, \\ 40096 Ústí nad Labem,
}

\begin{abstract}
The article describes the analysis of the durability and lifetime of selected interchangeable cutting inserts used for turning based on the wear measurement of the cutting tool, flank wear namely. The experiment was carried out on one type of material, such as stainless steel 1.4404 according to DIN EN 10088-3. The measurements were made on two turning inserts of the same type from two different manufacturers Sandvik coromant and Pramet tools. Evaluation of turning inserts wear was performed at four different cutting speeds. The value that was observed was the flank wear VB of the tool until the critical value was reached. Other different analysis have been performed, such as the length and shape of the chips analysis according to ISO 3685 . Based on the results of the measurements, it has been found that the Pramet insert, which has a thinner layer of coating, has reached a longer life and allows heat to flow out of the cutting area. It can be considered that thinner coating can positively contribute to better machining of stainless steels, which could be helpful for machining companies. Cutting inserts wear research is realized at the Faculty of Mechanical Engineering of Jan Evangelista Purkyně University in Ústí nad Labem.
\end{abstract}

Keywords: tool life, removable cutting inserts, tool wear, chip's evaluation, turning

\section{Introduction}

Currently, tools with removable inserts are used quite ordinary. This type of tool has many advantages - it eliminates the problem of joining the soldering insert with the tool holder, including the effect of tension after soldering. It also saves the cost of tool sharpening, saves time to remove the shank and to adjust the tool. In combination with $\mathrm{CNC}$ machines, these benefits are crucial. $[1,2]$

During the machining process, the tool is under influence of mechanical stress and a large amount of heat on the face and flank of the tool. The cutting insert, due to a combination of mechanical, thermal and chemical factors, gradually loses its cutting properties, [3, 4]. Wear on the cutting edge is changing tool geometry. Furthermore, the roughness of the contact points changes and the tool structure changes. [5] Throughout the machining process, the physical and chemical types of wear cause plastic deformation or brittle fracture which acts

\footnotetext{
* Corresponding author: karel.sramhauser@ujep.cz

Reviewers: Stanislaw Legutko, Augustín Görög
} 
suddenly and can cause an immediate machining operation. This result, for example, as the plastic deformation of the tool or nose breaking. Wearing mechanisms also depend on temperature. $[6,7]$

The reason for performing tool wear research is to record the actual course of wear, to evaluate the resulting wear and the ability to meet the cutting process requirements. All this in real time and machining environment. The type of selected turning inserts is similar for comparison purposes as well as cutting conditions. Tested materials are different, giving us a number of results that can be used by machining companies for the future choice of inserts purchase with regard to the most commonly used material or materials. $[8,9]$

\section{Materials and methods}

Research is carried out on several types of materials, such as steels for quenching and tempering or normalised steels, etc. The test described in this article is part of the research. Test was performed on steel class 1.4404 according to DIN EN 10088-3. This is corrosionresistant steel in an industrial environment, particularly resistant to pitting corrosion in the presence of chlorides, and especially resistant to sulfuric acid and phosphoric acid. Steel 1.4404 is weldable without the risk of intergranular corrosion in the area of thermal influence. It is suitable for cold forming and has good workability. Polishing is difficult to achieve mirror surface. Steel 1.4404 is used for welded constructions in aggressive industrial environments, for the manufacture of pressure vessels and components in the chemical, pharmaceutical and textile industries. This material can be used for food contact and dishes where high purity of the product is required. $[10,11,12]$

Table 1. Chemical composition of steel 1.4404 according to DIN EN 10088-3

\begin{tabular}{|c|c|}
\hline Element symbol & $\begin{array}{c}\text { Percentage content } \\
{[\mathbf{w t} \% \mathbf{]}}\end{array}$ \\
\hline $\mathrm{C}$ & $\leq 0.03$ \\
\hline $\mathrm{Mn}$ & $\leq 2.0$ \\
\hline $\mathrm{Si}$ & $\leq 1.0$ \\
\hline $\mathrm{Cr}$ & $16.5 \div 18.5$ \\
\hline $\mathrm{Ni}$ & $11 \div 14$ \\
\hline $\mathrm{Mo}$ & $2 \div 2.5$ \\
\hline $\mathrm{P}$ & $\leq 0.045$ \\
\hline $\mathrm{S}$ & $\leq 0.03$ \\
\hline
\end{tabular}

In this part of experiment, measurements were made on two rhomboidal-shaped removable turning inserts, namely on CNMG 120408E-M T9325 by Pramet (Fig. 2.) and CNMG 120408-PM 4325 by Sandvik (Fig. 3.). For measurement was used Olympus SZX10 stereomicroscope with measuring software in parallel. 


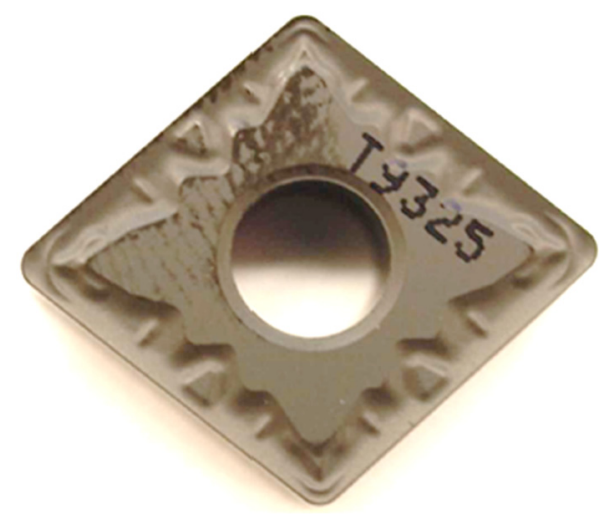

Fig. 1. Removable turning insert Pramet CNMG 120408E-M T9325

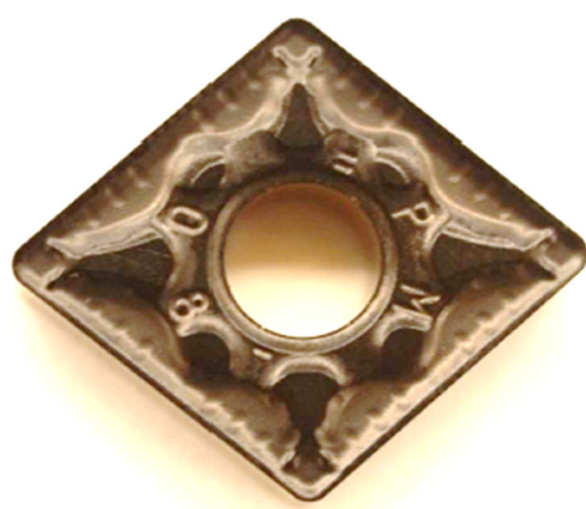

Fig. 2. Removable turning insert Sandvik CNMG 120408-PM 4325

As a part of research was also to performed EDS analysis for both turning inserts. EDS analysis of these plates (Figures 1. and 2.) was performed on the Tescan Vega 3 scanning electron microscope with the Bruker X-flash nano EDS analyzer. Based on the analysis carried out it was possible to conclude that Pramet CNMG 120408E-M T9325 (Fig. 3) is formed with a substrate and a double coat. The substrate consists of tungsten carbide, titanium carbide and cobalt binder. The top coating with a thickness of $7 \mu \mathrm{m}$ consists of $\mathrm{Al}_{2} \mathrm{O}_{3}$ with a measurable presence of titanium and carbon. The lower coat with a thickness of $6 \mu \mathrm{m}$ is formed by titanium carbide. The presence of oxygen, aluminum and tungsten can also be observed probably by diffusing $\mathrm{Al}$ and $\mathrm{O}$ from the topcoat and $\mathrm{W}$ from the substrate. Sandvik CNMG 120408-PM 4325 (Fig. 4) is also formed with the substrate and double coat. The substrate is composed of tungsten carbide with a cobalt binder. Top coated layer with thickness $6 \mu \mathrm{m}$, is composed of $\mathrm{Al}_{2} \mathrm{O}_{3}$. Lower coating with thickness $12 \mu \mathrm{m}$ is from the TiCN. $[13,14,15]$

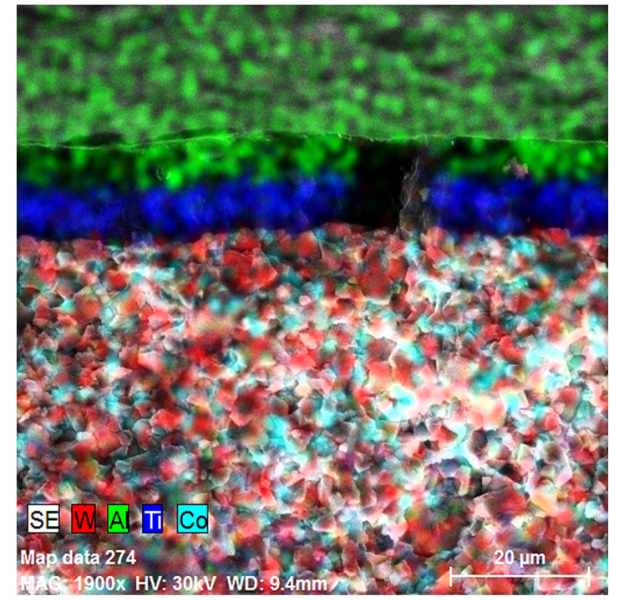

Fig. 3. Cross section of CNMG $120408 \mathrm{E}$ T9315

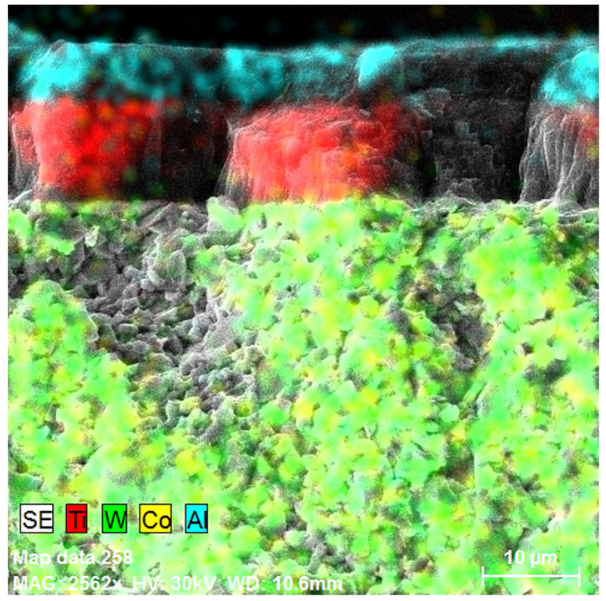

Fig. 4. Cross section of CNMG 432-PM 4325

The experimental material was turned on the three-axis CNC lathe DOOSAN Lynx 220L with the control system FANUC. For all operations was used tool holder PCLNR 2020 K12. The depth of cut $a_{p}$ was set at $1.5 \mathrm{~mm}$ because the system had an instability at depth of $2 \mathrm{~mm}$ 
offset. Feed rate $f$ was set to $0.3 \mathrm{~mm} \cdot \mathrm{ot}^{-1}$. The inserts were tested at cutting speeds $v_{c}=80 \mathrm{~m} \cdot \mathrm{min}^{-1}, 100 \mathrm{~m} \cdot \mathrm{min}^{-1}, 120 \mathrm{~m} \cdot \mathrm{min}^{-1} \mathrm{a} 140 \mathrm{~m} \cdot \mathrm{min}^{-1}$. The critical wear limit of VB $\mathrm{BAX}_{\mathrm{MAX}}$ was determined on $0.3 \mathrm{~mm}$.

\subsection{Chip shape and length evaluation}

Along with the measurement of $\mathrm{VB}_{\mathrm{MAX}}$ flank wear, the shape and the length of chips was continuously analyzed using the cut-off method. The reason to look at the chip shape is the fact that only some types of chip are ideal for machining because of the smoothness of the cutting process, and these changes of the chip during turning indicates a change in the geometry of the cutting tool. $[14,15]$

Chip length measurement by the cut-off method was performed on the Olympus SZX10 stereomicroscope (Fig. 5.). From each sample taken after the cutting cycles, 10 chips were selected that were most present in the sample set (type of shape). Chips were evaluated by ISO 3685. [16]

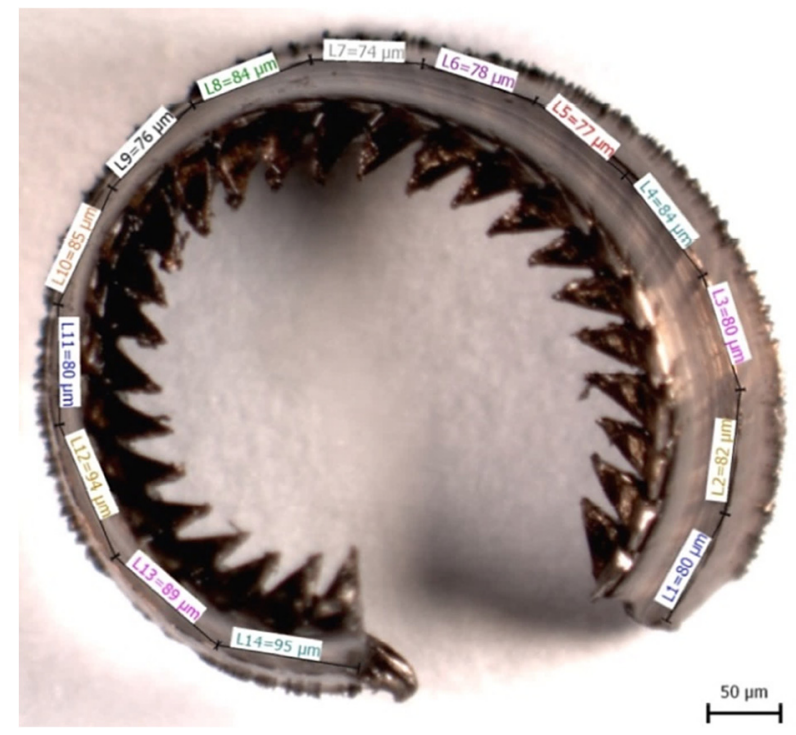

Fig. 5. Chip measurement by the cut-off method

\section{The results and discussion}

During the measurement the VB $\mathrm{B}_{\mathrm{MAX}}$ wear on the tool's flank was photographed based on visual evaluation. The result of photographic recording is a series of frames with the current wear value, which is used as the input data to create a real-time wear curve to depend on time. During machining stainless steel, the build-up-edge was created, as with titanium alloys. Because of this, it was necessary to distinguish optically between accumulated machined material on the tool and a really worn surface. The VB wear was measured from the initial level (due to plastic deformation) to the visible worn portion of the tool coating.

Fig. 6 shows reached maximal wear limit at Pramet CNMG 120408E-M T9325. The picture shows a flank wear of value $312 \mu \mathrm{m}$. There is also built-up-edge (BUE), probably due to the low cutting speed, and at the end of the flank wear area, you can see the notch wear, which is a common wear type when machining stainless steels.

Fig. 7 shows reached maximal wear limit at Sandvik CNMG 120408-PM 4325. The flank 
wear value is $307 \mu \mathrm{m}$. There is built-up edge and flank wear as similar as at Fig. 6. Unlike the Pramet insert, Sandvik CNMG 120408-PM 4325 has a built-up edge closely to tool tip.

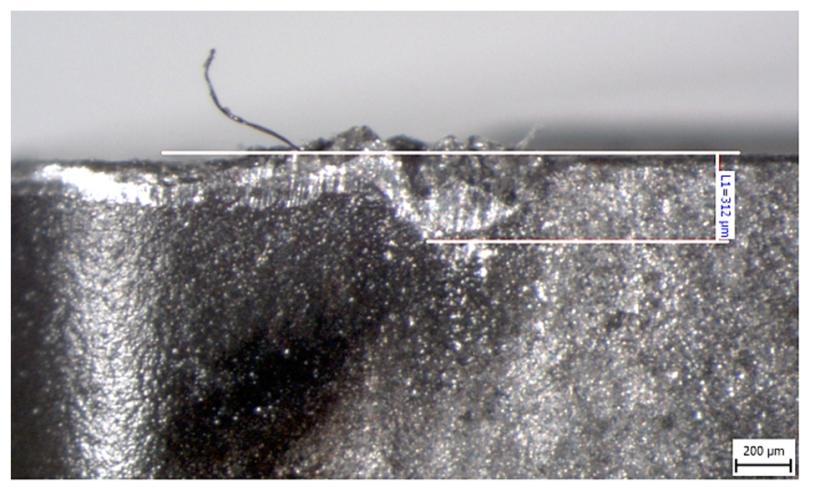

Fig. 6. VBMAX wear of CNMG $120408 \mathrm{E}-\mathrm{M}$ T9325, $\left(v_{c}=100 \mathrm{~m}^{\prime} \mathrm{min}^{-1}, T=23 \mathrm{~min}\right)$

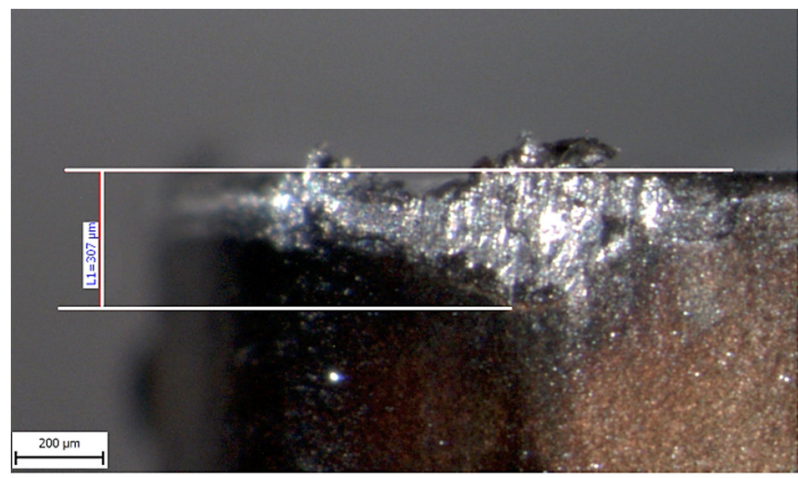

Fig. 7. VBMAX wear of CNMG 120408-PM 4325, $\left(v_{c}=100 \mathrm{~m}^{\prime} \mathrm{min}^{-1}, T=15 \mathrm{~min}\right)$

According to the measured values of wear of the Pramet CNMG 120408E-M T9325 (Fig. 7.), it is apparent that the lowest life of the cutting edge was manifested at the cutting speed $v_{c}=140 \mathrm{~m} \cdot \mathrm{min}^{-1}$. Shortly thereafter, the trend of wear was followed at cutting speeds $v_{c}=120 \mathrm{~m} \cdot \mathrm{min}^{-1}$ a further $v_{c}=100 \mathrm{~m} \cdot \mathrm{min}^{-1}$. From the course of wear dependence at cutting speed $v_{c}=80 \mathrm{~m} \cdot \mathrm{min}^{-1}$ there is a repetitive built-up-edge on the tool, probably due to a lower cutting temperature at the tip of the tool nose.

The wear process data of the Sandvik CNMG 120408-PM 4325 was evaluated in the same way. The lowest lifetime of the cutting edge was at the cutting speed $v_{c}=140 \mathrm{~m} \cdot \mathrm{min}^{-1}$. Additionally, the wear rate at cutting speeds $v_{c}=100 \mathrm{~m} \cdot \mathrm{min}^{-1}$ and $v_{c}=120 \mathrm{~m} \cdot \mathrm{min}^{-1}$ was followed. The course of wear at cutting speed $v_{c}=80 \mathrm{~m} \cdot \mathrm{min}^{-1}$ is similar to that of Pramet CNMG 120408E-M T9325. Again, a recurrent increase in the flank wear of the tool is evident.

Fig. 8 shows the comparison of the lengths of the time $\mathrm{T}[\mathrm{min}]$ until the $\mathrm{VB}_{\mathrm{MAX}}[\mu \mathrm{m}]$ is reached, depending on the cutting speeds $\mathrm{v}_{\mathrm{c}}\left[\mathrm{m} \cdot \mathrm{min}^{-1}\right]$. The comparison shows that the same or better results on tested steel class 1.4404 according to DIN EN 10088-3 have been achieved by Pramet CNMG 120408E-M T9325. 


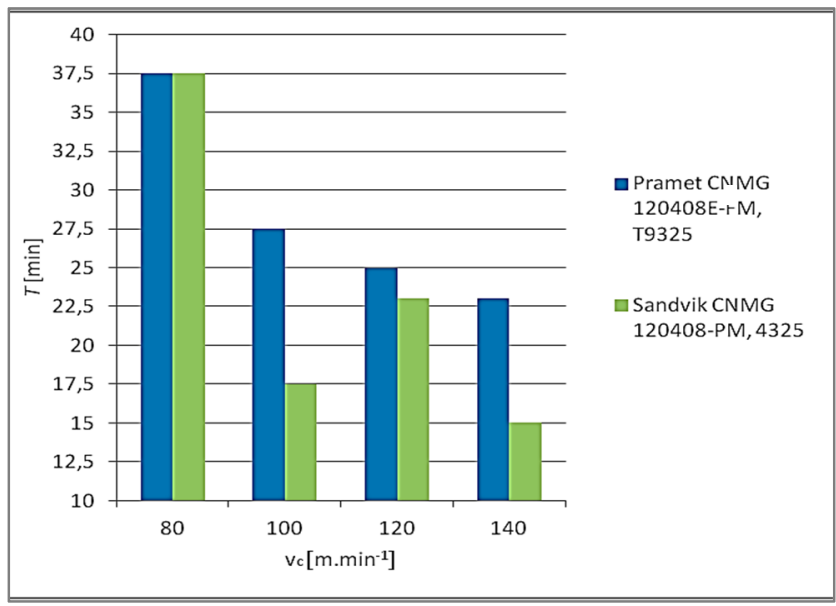

Fig. 8. Comparison of turning inserts wear time depending on cutting speeds

The coated layer on the Sandvik CNMG 120408-PM 4325 is about $5 \mu \mathrm{m}$ thicker. Machining of stainless steels is difficult in creating built-up edge, making notch wear and also increasing wear due to high temperatures.

When we did machining basic, quality or miscellaneous steels of earlier parts of research, a thicker coated layer contributed to longer tool life. Based on the experiment data, it can be said that during machining stainless steel, the coating layer behave like a thermal insulator and thus mislead the heat from the cutting area. This results in higher wear due to higher temperatures.

In this part of experiment, three types of chips were produced according to ISO 3685 during machining. In majority, arch loose chips and arch connected chips, both of which were approximately the same. Elemental chips were restricted in two cases, at Sandvik CNMG 120408-PM 4325 at a cutting speed of $100 \mathrm{~m} \cdot \mathrm{min}^{-1}$ and at Pramet CNMG 120408 E-M T9325 at a cutting speed $120 \mathrm{~m} \cdot \mathrm{min}^{-1}$, however, only in a small amount. The size of the analyzed chips based on the cut-off method was very similar to most of the experiment, approximately $6 \mathrm{~mm}$, except for CNMG 120408E-FM VBD turning, T9325 with a cutting speed $v_{c}=140 \mathrm{~m} \cdot \mathrm{min}^{-1}$, with arched chips appeared to be about twice as large as all other measurements $(12 \mathrm{~mm})$. Tab. 2. shows evaluation of the shapes and lengths of the chips on average for the individual cutting speeds.

Table 2. Chip evaluation on cutting speeds

\begin{tabular}{|c|c|c|}
\hline \multirow{2}{*}{$\begin{array}{c}\text { Cutting speed } \\
\boldsymbol{v}_{\boldsymbol{c}}\left[\mathbf{m} \cdot \mathbf{m i n}^{-1}\right]\end{array}$} & \multicolumn{2}{|c|}{ Cutting insert type } \\
\cline { 2 - 3 } & $\begin{array}{c}\text { Pramet CNMG } \\
120408 \mathrm{E}-\mathrm{FM} \text { T9325 }\end{array}$ & $\begin{array}{c}\text { Sandvik CNMG } \\
120408 \text {-PM } 4325\end{array}$ \\
\cline { 2 - 3 } & \multicolumn{2}{|c|}{ Chip type / Chip lenght $\boldsymbol{l}$ [mm] } \\
\hline 80 & arch loose $/ 6 \div 16$ & $\begin{array}{c}\text { arch loose, } \\
\text { arch connected } / 4 \div 7\end{array}$ \\
\hline \multirow{2}{*}{100} & $\begin{array}{c}\text { arch loose, } \\
\text { arch loose, } \\
\text { arch connected, } \\
\text { elemental/ } 6 \div 8\end{array}$ \\
\hline 120 & $\begin{array}{c}\text { elemental } \\
\text { arch loose } / 4.3 \div 6.8\end{array}$ & $\begin{array}{c}\text { arch loose, } \\
\text { archnected } / 6 \div 8\end{array}$ \\
\hline 140 & $\begin{array}{c}\text { arch loose, } \\
\text { arch connected } / 4.3 \div 6.8\end{array}$ & arch loose $/ 6 \div 8$ \\
\hline
\end{tabular}




\section{Conclusion}

The paper describes the method and process of measuring the wear of the selected removable insert for turning. The analysis was performed under the given cutting conditions and parameters. Analyzed cutting inserts were Pramet CNMG 120408E-M T9325 and Sandvik CNMG 120408-PM 4325, tested material was steel class 1.4404 according to DIN EN 100883. Based on the entry tests, the wear time dependence for a given inserts was examined at different cutting speeds, at $v_{c}=80,100,120 \mathrm{a} 140 \mathrm{~m} \cdot \mathrm{min}^{-1}$. Better results, or longer lifetime, were achieved by the Pramet CNMG 120408E-M T9325. In addition to the cutting speed $v_{c}=140 \mathrm{~m} \cdot \mathrm{min}^{-1}$, where the Pramet and Sandvik inserts values would be virtually the same. The reason for the better results of Pramet insert was that the weaker coated layer allowed the heat to drain from the edge to reduce the heat load of the tool. During the measurement, were also evaluated chips by the cut-off method. According to ISO 3685 were most common arch loose, arch connected or elemental chips included. Based on the results of the measurements, it can be said that a thinner coating may contribute positively to better machining of stainless steels.

Authors are grateful for the support of grant No. CZ.1.05/4.1.00/11.0260 EDIMARE and SGS FME JEPU in Ústí nad Labem for 2018.

\section{References}

1. K. Kocman, Technologické procesy obrábění. (CERM, Brno, 2011)

2. J. Beddoes, M. J. Bibby, Principles of Metal Manufacturing Processes. (Antony Rowe, Eastbourne, 2003)

3. J. Madl, V. Shubert, Experimentální metody a optimalizace v teorii obrábění. (ČVUT, Praha, 1985)

4. J. Jurko, Opotrebenie rezných nástrojov. (Prešov, 2005)

5. G. M. Krolczyk, P. Nieslony, S. Legutko, Determination of tool life and research wear during Duplex Stainless Steel turning. Archives of Civil and Mechanical Engineering, 15(2), 347-354, (2015)

6. J. Brychta, R. Cep, J. Novakova, L. Petrkovska, Technologie II - 2. díl. (VŠB - TU Ostrava, 2008)

7. J. Majerik, I. Barenyi, Wear and Tool Life Investigation of Carbide Inserts while Hard Machining of Armox 500 Steel. Manufacturing Technology, 18(2), 273-278, (2018)

8. G. Krolczyk, S. Legutko, P. Raos, Cutting edge wear examination during turning of Duplex Stainless Steel. Tehnicki Vjesnik - Technical Gazette, 20(3), 413-418, (2013)

9. G. Krolczyk, M. Gajek, S. Legutko, Predicting the tool life in the dry machining of Duplex Stainless Steel. Eksploatacja i Niezawodnosc - Maintenance and Reliability, 15(1), 62-65, (2013)

10. J. Leinveber, P. Vavra, Strojírenské tabulky. (Úvaly, 2011)

11. N. Naprstkova, J. Cais, P. Kraus, M. Tavodova, Using of electron microscopy for tool wear evaluation., (2017)

12. J. Madl, M. Vrabec, J. Kafka, R. Dvorak, Technologie obráběni I.dil. (ČVUT Praha, 1999)

13. A. Michalski, A. Sokolowska, S. Legutko, The useful properties of TiNx-Ti coatings deposited onto drills at $500 \mathrm{~K}$ using the Reactive Pulse Plasma method. Thin Solid Films, 129(3-4), 249-254, (1985) 
14. P. Twardowski, S. Legutko, G. M. Krolczyk, et al., Investigation of wear and tool life of coated carbide and cubic boron nitride cutting tools in high speed milling. Advances in Mechanical Engineering, 7(6) (2015)

15. G. Krolczyk, M. Gajek, S. Legutko, Effect of the cutting parameters impact on tool life in Duplex Stainless Steel turning process. Tehnicki Vjesnik - Technical Gazette, 20(4), 587-592 (2013)

16. ISO 3685. Tool-life testing with single-point turning tools. (1993) 